\title{
Anterior Tooth Discrepancy in Different Bangladeshi Malocclusion Group at BSMMU
}

\author{
MN HASAN $^{\mathrm{a}}$, GS HASSAN ${ }^{\mathrm{b}}$, T RAFIQUE ${ }^{\mathrm{c}}$, MK ALAM ${ }^{\mathrm{d}}$
}

\begin{abstract}
Summary:
Anterior tooth discrepancy, an important clinical orthodontic tool to manage malocclusions, may vary on different race, ethnicity and gender. Therefore this study on anterior tooth discrepancy of Bangladeshi malocclusion groups were formulated to calculate and set up a standard norm, and to evaluate the gender discrepancy. A cross sectional type study was done among 207 pretreated dental casts (60 male, 147 female) of malocclusion patient at the Department of
\end{abstract}

\section{Introductions:}

The successful finishing of orthodontic treatment and post-treatment stability of dental occlusion treated with orthodontic management greatly depends on pretreatment tooth size discrepancy of individual occlusion $^{1}$. Tooth discrepancy is defined as a disproportion among the mesio-distal widths of the maxillary and mandibular teeth of individuals ${ }^{2}$. To determine the possible functional and aesthetic extent of treatment, an orthodontist usually considers the proportional relationship between the maxillary and mandibular tooth sizes as an important index. Without

a. Dr. Md. Nazmul Hasan, Assistant Professor \& Head, Department of Orthodontics \& Dentofacial Orthopedics, Update Dental College \& Hospital, Turag, Dhaka.

b. Dr. Gazi Shamim Hassan, Chairman, Department of Orthodontics, Faculty of Dentistry, Bangabandhu Sheikh Mujib Medical University (BSMMU), Bangladesh.

c. Dr. Tanzila Rafique, Medical Officer,Department of Orthodontics, Faculty of Dentistry, Bangabandhu Sheikh Mujib Medical University (BSMMU), Bangladesh.

d. Dr. Mohammad Khursheed Alam, Senior lecturer, Orthodontic Unit, School of Dental Sciences, University Sains Malaysia, Kelantan, Malaysia

Address of Correspondence: Dr. Md. Nazmul Hasan, Assistant Professor\& Head, Department of Orthodontics \& Dentofacial Orthopedics, Update Dental College \& Hospital, Turag, Dhaka 1711, Bangladesh, Phone: +8801817097748 , e-mail: nazmul2246 @yahoo.com,mn.hasan@updatedentalcollege.edu.bd

Received: 24 October, 2013

Accepted: 23 April, 2015
Orthodontics, Faculty of Dentistry, BSMMU, Bangladesh. Bolton anterior ratio were measured and compared statistically (in the Angle's group of malocclusion). No significant anterior discrepancy was observed between Bangladeshi male and female groups. A similar value for anterior discrepancy was observed in neighboring countries.

Key words: Anterior tooth discrepancy, Malocclusion.

(J Banagladesh Coll Phys Surg 2015; 33: 191-194)

the proper mesio-distal tooth size ratio between the maxillary and mandibular teeth, correct co-ordination of arches with orthodontic treatment would be difficult ${ }^{3}$. Differences in tooth size have been associated with different ethnic backgrounds and occlusion status ${ }^{4}$. Several methods have been described to measure the inter-arch tooth size disproportion ${ }^{5,6}$, However Bolton's analysis ${ }^{6}$ is one of the most popular methods for determining tooth size abnormality. It is useful in aiding diagnosis as well as treatment planning. Clinically, Bolton's ratios have been used to determine the need for reduction of tooth size via inter-proximal stripping or for the addition of tooth size via prosthetic restoration.

Several studies have been conducted around the world to establish the national and ethnic norm. However only two study have been reported among Bangladeshi population comparing the normal occlusion with malocclusion ${ }^{1}$. Hence this study was undertaken in a tertiary level of Hospital at the department of Orthodontics, Bangabandhu Sheikh Mujib Medical University (BSMMU), Dhaka, where sample malocclusion group were larger to ensure a more specific norm representing the Bangladeshi population with few goals. Firstly, determining the sexual dimorphism of tooth size discrepancy. Secondly, investigating the corelation between anterior tooth size discrepancies and angle's malocclusions (class I, class II, class III), as well as their prevalence in Bangladeshi populations. Lastly, to obtain a nominative data on tooth size discrepancies among Bangladeshi malocclusion group. 


\section{Material and Methods:}

This was a cross sectional type study conducted in the Department of Orthodontics, Bangabandhu Sheikh Mujib Medical University (BSMMU) from January 2007 to June 2010. From the record of 350 pretreated dental casts of the department, by purposive sampling, the study samples, 207 pretreatment dental casts of orthodontic patients (Bangladeshi individuals) of both male (60) and female (147) with malocclusion were selected those fulfilling the inclusion criteria. The inclusion criteria were:

a. Presence of all six permanent anterior teeth on both maxilla and mandible without any supernumerary or accessory teeth.

b. All these teeth assed to be morphologically normal without any occlusal abrasion, attrition, caries, restoration, cracked or fracture crown and without any previous history of proximal striping and orthodontic treatment.

They were then categorized into three malocclusion group according to Edward H Angle ${ }^{7}$ : Class I, Class II, Class III (Table I). The mesio-distal diameter of each anterior teeth were recorded at maximum diameter of individual tooth when measurement were appear parallel to occlusal plane and labial surface of that tooth by using a sliding caliper with vernier scale and graded gauge (Mitutoyo, Japan). Measurements were carried out with a reading accuracy of $0.1 \mathrm{~mm}$. All those data ware measure twice, if the second measurement differ by more than $0.2 \mathrm{~mm}$ from the first measurement, re-measurement were carried out. Recorded data then collected by a structured data collection sheet and anterior teeth discrepancy were calculated by Bolton ${ }^{6}$ formula as below:

Anterior teeth discrepancy $=[$ (sum of mesio-distal width of mandibular six Anterior teeth) $\div$ (sum of mesio-distal width of maxillary six anterior teeth) $\times 100$ ]
Statistical analyses were performed by using SPSS 16.0 (Chicago, IL) software with a provability level of 0.05 considered to be statistically significant. Analysis of variance (ANOVA) was used to determine the statistical significant difference between mean. Bolton anterior tooth size ratios as a function of Angle's classification as well as sex. The same researcher performed all measurements and reproducibility of the method were tested by re-measuring randomly selected thirty pairs (10 pairs from each group) of dental cast and tested with Wilcoxon nonparametric test (Table 2).

\section{Results:}

Out of 350 dental casts, 207 those fulfilling the inclusion criteria were studied. Among those 207 dental casts, 112 (male 32, female 80) were grouped in class I malocclusion, 80 (male 22, female 85 ) were class II and 15 (male 6, female 9) in class III malocclusion (Table I). The tooth size discrepancies were determined using the published ratio as described by Bolton's $77.2 \pm 1.65 \%$ for the anterior ratios within \pm 1 SD were considered "normal," and those greater than \pm 1 SD were labeled as having a tooth size discrepancy ${ }^{6}$.

The present study shows having discrepancy (as having more than $\pm 1 \mathrm{SD}$ ) in both male and female malocclusion group of Bangladeshi population but without having any significant dimorphism for tooth size discrepancy between these two sex groups (Table III). In our present study on Class I malocclusion group, the mean Bolton ratio for anterior teeth were measured 78.26 \pm 2.71 . This finding indicates the presence of tooth tissue discrepancy in Class I malocclusion group. Moreover, in case of Class II and Class III malocclusion groups of Bangladeshi population, this study also exhibited presence of tooth size discrepancy compare with that of Bolton's reference value (Table IV).

\section{Table-I}

Distribution of Malocclusion group with age and gender $(n=207)$.

\begin{tabular}{|c|c|c|c|c|c|}
\hline \multirow[t]{2}{*}{ Malocclusion groups } & \multicolumn{3}{|c|}{ Age(years) } & \multicolumn{2}{|c|}{ Sex } \\
\hline & Range & Mean & $\mathrm{SD}( \pm)$ & Male & Female \\
\hline Class-I & $12-36$ & 19.18 & \pm 5.71 & 32 & 80 \\
\hline Class-II & $12-30$ & 18.52 & \pm 4.99 & 22 & 58 \\
\hline Class-III & $12-25$ & 17.86 & \pm 5.34 & 6 & 9 \\
\hline
\end{tabular}


Table-II

\begin{tabular}{|c|c|c|c|c|c|c|c|}
\hline \multicolumn{8}{|c|}{ Comparison between two measurements of tooth size Discrepancies. } \\
\hline Group & Measurement & $\mathrm{n}$ & Minimum & Maximum & Mean & SD & $P$ value \\
\hline \multirow[t]{2}{*}{ Class I } & 1 & 10 & 76.0 & 84.0 & 80.2 & 1.6 & .176 \\
\hline & 2 & 10 & 77.2 & 83.5 & 80.0 & 1.6 & \\
\hline \multirow[t]{2}{*}{ Class II } & 1 & 10 & 75.8 & 80.0 & 78.2 & 1.4 & .183 \\
\hline & 2 & 10 & 75.9 & 80.2 & 78.2 & 1.3 & \\
\hline \multirow[t]{2}{*}{ Class III } & 1 & 10 & 74.5 & 84.9 & 79.0 & 1.8 & .155 \\
\hline & 2 & 10 & 75.5 & 84.9 & 79.9 & 1.9 & \\
\hline
\end{tabular}

Table-III

Mean Bolton anterior ratios of all subjects of malocclusion groups as a function of gender.

\begin{tabular}{lccccc} 
Gender & Sample size $(\mathrm{n})$ & Mean & Standard Deviation $(\mathrm{SD})$ & Range & p value \\
\hline Male & 60 & 79.23 & \pm 2.38 & $73.79-87.09$ & 0.02 \\
Female & 147 & 80.13 & \pm 2.39 & $72.45-86.02$ & \\
\hline
\end{tabular}

Table-IV

\begin{tabular}{lccc}
\multicolumn{3}{c}{$\begin{array}{c}\text { Distributions of Teeth discrepancy with Angle's } \\
\text { malocclusion groups. }\end{array}$} \\
Malocclusion & \multicolumn{3}{c}{ Bolton Anterior Ratio } \\
\cline { 2 - 4 } groups & Mean & $\mathrm{SD}( \pm)$ & Range \\
\hline Class-I & 78.26 & \pm 2.71 & $74.51-85.62$ \\
Class-II & 76.28 & \pm 1.99 & $71.37-77.28$ \\
Class-III & 79.76 & \pm 2.34 & $73.71-91.90$ \\
\hline
\end{tabular}

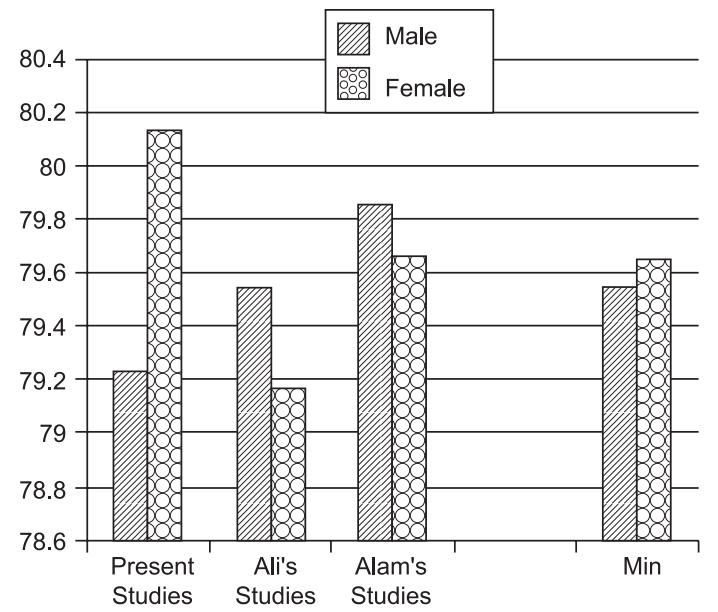

Fig.-1: Bar chart showing comparative Bolton ratio for anterior tooth in the different Bangladeshi populations and their mean value for both genders.

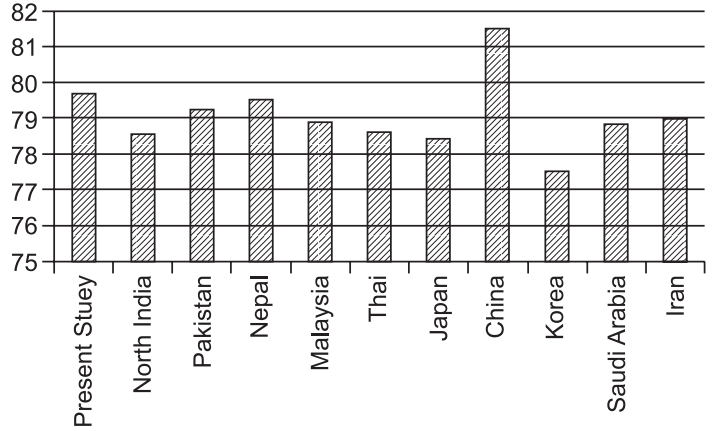

Fig.-2: A comparative representation of our present study's anterior ratio with that of other Asian country populations: Northern India ${ }^{10}$, Pakistan ${ }^{11}$, Nepal ${ }^{12}$,

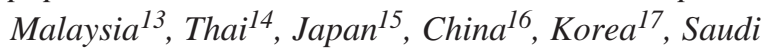
Arabia $^{18}$, and $\operatorname{Iran}^{19}$.

\section{Discussion:}

In 1958, Bolton ${ }^{6}$ studied 55 Caucasian subjects having normal occlusion where his mean anterior ratio value was 77.2. Where as in other study ${ }^{1,8,9}$ on Bangladeshi population the Bolton ratio were also measured in different group of normal population comparing that of with malocclusion group is also close to our present study. In the earlier study, the anterior Bolton ration of Bangladeshi population by Ali $\mathrm{MW}^{8}$ was calculated 79.55 for male and 79.17 for female. However they 
calculated their ratio with comparing a referral 50 normal occlusion group ( 25 female and 25 male). And their total sample sizes for malocclusion group were 150. Although the other study on Bangladeshi population by Alam $\mathrm{MK}^{9}$ were conducted with a larger sample size (260) however the malocclusion group constitute with 160 sample and the rest 100 sample were normal occlusion group. In that study malocclusion group were divided by spacing (73 samples) and crowding (87 samples) group not on the basis of Angle's classification of malocclusion. Whereas the present study constitute with 207 malocclusion individual grouped into angles classification of malocclusion. A comparative study among these three study (present study and two other previous study) reveals the average anterior tooth ratio for male 79.55\% and for female 79.65\% in Bangladeshi population (Fig.-1). Moreover in our present study average anterior ratio for Bangladeshi population has been calculated 79.68\% (Fig.-2).

In comparison to present study on Bangladeshi population's anterior teeth ratio with that of the others study on Asian population (India ${ }^{10}$, Pakistan ${ }^{11}$, Nepal ${ }^{12}$, Malaysia $^{13}$, Thai ${ }^{14}$, Japan ${ }^{15}$, China ${ }^{16}$, Korea ${ }^{17}$, Saudi Arabia ${ }^{18}$, and $\operatorname{Iran}^{19}$ ) shows similar finding.

\section{Conclusion:}

Gender differences in the anterior tooth discrepancy in Bangladeshi malocclusion group were not significant. A mean value of anterior tooth discrepancy has been calculated for Bangladeshi malocclusion group which is closer to other neighboring country population in compare to the rest other population in the world.

\section{Acknowledgement:}

We would like to express our gratitude and thanks to Prof. Dr. Md. Zakir Hossain, Head, Department of Orthodontics, Dhaka Dental College and Hospital, Dhaka, Bangladesh for his valuable suggestions and guidance during proposal preparation and conclusion drawing of this study.

\section{References:}

1. Hasan MN, Chowdhury SS, Khan MAA, Taleb A, Abid MMA. "Tooth-size Discrepancy" -an important diagnostic tool to measure the out-come of Orthodontic Treatment Completion: A Review. Bangladesh Journal of Dental Research \& Education, 2011; 1(1): 27-29.

2. Othman SA, Harradine NWT. Tooth-size Discrepancy and Bolton's Ratio: a literature review, Journal of Orthodontics. 2006;33: 45-51.
3. Crossby DR, Alexander CG. The occurrence of tooth size discrepancies among different malocclusion groups. American Journal of Orthodontics and Dentofacial Orthopedics. 1989;95: 457- 61.

4. Yonezu T, Warren JJ, Bishara SE, Steinbock KL. Comparison of tooth size and dental arch widths in contemporary Japanese and American preschool Children. World J Orthod 2001;2:356-60.

5. Zilberman O, Huggare JAV, Parikakis KA. Evaluation of the validity of tooth size and arch width measurements using conventional and 3-dimensional virtual orthodontic models. Angle Orthodontic journal; 2003; 73: 301-6.

6. Bolton WA, The clinical application of tooth-size analysis. American Journal of Orthodontics and Dentofacial Orthopedics. 1962;48: 504.

7. Angle EH. Treatment of malocclusion of the teeth and fracture of maxillae. In:Angle's system, ed 6. Philadelphia: SS White Dental Mfg Co; 1900.

8. Ali W, Hossain MZ. A Study on Bolton Anterior Tooth Size Discrepancies among Different Malocclusion Groups. Bangladesh Journal of Orthodontics \& Dentofacial Orthopedics. 2011; 1(2);1-4.

9. Alam MK, Ida J. Overjet, overbite and dental midline shift as predictors of tooth size discrepancy in a Bangladeshi population and a graphical overview of global tooth size ratios. Acta Odontologica Scandavica. Epub Ahead of Print. 26 March 2013;1-12.

10. Rekha S, Sushil K, Anu S. Prevalence of tooth size discrepancy among North Indian orthodontic patients. Contemp Clin Dent 2011;2:170-5.

11. Batool I, Abbas A, Rizvi SA, Abbas I. Evaluation of tooth size discrepancy in different malocclusion groups. J Ayub Med Coll Abbottabad 2008;20:51-4.

12. Jaiswal AK, Paudel KR. Applicability of Bolton's tooth size ratio for Nepalese population. J Nepal Dent Ass 2009;10:84-7.

13. Rahman ANAA, Othman SA. Comparison of tooth size discrepancy of three main ethnics in Malaysia with Bolton's ratio. Sains Malaysiana 2012;41:271-5.

14. Ho CT, Freer TJ. The graphical analysis of tooth width discrepancy. Aust Orthod J 1994;13:64-70.

15. Endo T, Shundo I, Abe R. Applicability of Bolton's tooth size ratios to a Japanese orthodontic population. Odontology 2007;95:57-60.

16. Nie Q, Lin J. Comparison of intermaxillary tooth size discrepancies among different malocclusion groups. Am J Orthod Dentofacial Orthop 1999;116:539-44.

17. Lee SJ, Moon SC, Kim TW, Nahm DS, Chang YI. Tooth size and arch parameters of normal occlusion in a large Korean sample. Korean J Orthod 2004;34:473-80.

18. Alkofide E, Hashim HA. Intermaxillary tooth size discrepancies among different malocclusion Classes: a comparative study. J Clin Pediatr Dent 2002;26:383-7.

19. Mirzakouchaki B, Shahrbaf S, Talebiyan R. Determining tooth size ratio in Iranian-Azari population. J Contemp Dent Pract 2007;7:86-93. 